\title{
Experience of Public Health Midwives as Nutrition Counselors for Mothers and Care Givers of Children Aged 6-36 Months in Eastern Province of Sri Lanka
}

\author{
Sujendran $\mathrm{S}^{1 *}$, Senarath $\mathrm{U}^{2}$ and Joseph $\mathrm{J}^{1}$ \\ ${ }^{1}$ Department of Supplementary Health Sciences, Faculty of Health-Care Sciences, Eastern University, Sri Lanka \\ ${ }^{2}$ Department of Community Medicine, Faculty of Medicine, University of Colombo, Sri Lanka
}

\begin{abstract}
Knowing about the clients is the central aspect of health care practice. This study aimed to explore the essences of the lived experience of Public Health Midwives (PHMs) as primary care givers to the children and nutrition counselors for mothers and care givers. The methodology of the study was interpretive phenomenology described by Heidegger. There were three Focus Group Discussions (FGD) involving six PHMs in each FGD. Altogether, eighteen PHMs participated in the in-depth experiential conversations using an FGD guide. The discussions were video and audio recorded and transcribed. Thematic analysis and interpretation were carried out according to van Manen. Four major themes have emerged through the interpretation process. The themes were: (1) habit of fast food, (2) busy life of mothers and care givers and (3) lack of knowledge among mothers and care givers (4) lack of health care personnel. A sub theme 'critical financial situation' was also emerged under the theme busy life of mothers and care givers and another sub theme 'interference by mother-in-laws in child nutrition' was emerged from within the major theme, lack of knowledge among mothers and care givers. The study was quite specific to Eastern province of Sri Lanka, where the nutritional status of the children aged 6-36 months was lower than the average level during the study period. The findings of the study will be helpful to the health care personnel in the Eastern province; in planning and providing the optimum care to children aged 6-36 months and nutrition counseling for their mothers and care givers in future.
\end{abstract}

Keywords: Lived experience; Nutritional awareness; Interpretive phenomenology; Hermeneutic circle; Thematic analysis

\section{Introduction}

People living in the Eastern province of Sri Lanka have been coming out from their war turn lifestyle since the end of war in 2009. The civil war which extended for more than 3 decades has negatively affected the status of these people in all aspects. Undernutrition among children in the preschool age is higher in the Eastern province than in the rest of the country. According to the Sri Lanka Demographic and Health Survey 2006-07, the prevalence of wasting in the Eastern province was $20.0 \%$, which is higher than the average wasting (14.8\%) in other parts of the country [1].

In spite of infant and young child feeding counseling and other measures carried out by Public Health Midwives (PHMs), many children cannot access these services because of their poverty or pecuniary embarrassment, poor knowledge and many other reasons. The purpose of this study was to explore the feelings and experiences of PHMs as nutrition counselors for mothers and care givers. The essence of their lived experience can be a useful tool for planning future job descriptions for PHMs in Sri Lanka.

\section{Research question}

What does it mean for Public Health Midwives to be nutrition counselors for mothers and care givers of children aged 6-36 months?

\section{Review of Literature}

The goal of phenomenological research is not to describe a grand theory or develop a model but to describe accurately a person's 'lived' experience in relation to what is being studied [2]. Phenomenology supports the re-examination of a taken-for-granted experience and, through examining the qualities of the experience, and allows us to identify its essence. Although there is considerable literature about the nutritional management of the preschool children, there is paucity of literature regarding the lived experience of health care personnel in nutritional counseling. King and Thomas investigated the lived experiences of fourteen critical care nurses about the caring of dying participants [3]. An encompassing theme of 'promises to keep' emerged, with five subthemes. The essence of intensive care nurses' lived experience of caring for dying participants is captured in the theme.

The United States Agency for International Development's Infant and Young Child Nutrition Project and PATH's prevention of mother-to-child transmission of HIV team conducted an infant feeding assessment in Eastern and Western Provinces in Kenya in 2007-08. It was a qualitative and participatory in-depth approach focusing on feeding practices of HIV-positive mothers of children younger than 2 years. The team found that feeding practices for infants and young children in Eastern and Western provinces of Kenya were strongly influenced by cultural beliefs related to breastfeeding and complementary feeding [4].

*Corresponding author: Sujendran S, Department of Supplementary Health Sciences, Faculty of Health-Care Sciences, Eastern University, Sri Lanka, Tel: +9471486618, Fax: +94652222059; E-mail: sankarapillaisujendran@gmail.com

Received April 19, 2015; Accepted May 20, 2015; Published May 25, 2015

Citation: Sujendran S, Senarath U, Joseph J (2015) Experience of Public Health Midwives as Nutrition Counselors for Mothers and Care Givers of Children Aged 6-36 Months in Eastern Province of Sri Lanka. J Nutr Disorders Ther 5: 161 doi:10.4172/2161- 0509.1000161

Copyright: (c) 2015 Sujendran S. This is an open-access article distributed under the terms of the Creative Commons Attribution License, which permits unrestricted use, distribution, and reproduction in any medium, provided the original author and source are credited. 


\section{Methodology}

There are several qualitative research approaches such as phenomenology, grounded theory, ethnography, historical research, action research and feminist research [5]. This study followed Heidegger's (1927) principles of phenomenology and van Manen's (1990) six methodological activities of the hermeneutic phenomenological approach [6]. Phenomenology has been and continues to be an integral field of inquiry that cuts across philosophic, sociologic and psychological disciplines [7].

Van Manen suggested six activities as a methodological structure of human science research. The activities mentioned below were followed in the investigation of the lived experience of participants in nutrition counseling to mothers and care givers, using the hermeneutic phenomenological approach:

1) Turning to a phenomenon which seriously interests us and commits us to the world;

2) Investigating experience as we live it rather than as we conceptualize it;

3) Reflecting on the essential themes which characterize the phenomenon;

4) Describing the phenomenon through the art of writing and rewriting;

5) Maintaining a strong and oriented pedagogical relation to the phenomenon;

6) Balancing the research context by considering parts and whole [6].

Each activity was explained clearly. The nature of the study settings, the researcher and the ethical considerations of the study were outlined. The process of analysis and interpretation was described. The hermeneutic circle, as a major tool of interpretation in this study, was explained.

\section{Design and sample}

This was an interpretive study which was conducted among Public Health Midwives (PHMs), in Batticaloa and Kalmunai health districts in the Eastern province of Sri Lanka during August-December, 2013. Among these PHMs, eighteen were recruited as participants. They shared their experience in three Focus Group Discussions. There were six participants in each focus group. We maintained a close rapport with these PHMs and other personnel in order to understand them deeply.

Permission was obtained from the two Regional Directors of Health Services (RDHS) to invite PHMs who provide nutrition counseling of children aged 6-36 months. An information sheet that outlines the details of the study was circulated to all potential PHMs inviting them to participate in the study. The researcher visited each Medical Officer of Health office and identified appropriate participants with the help of the Public Health Nursing Sisters in-charge of the PHMs. The researcher individually approached the participants and invited them to participate in the study. Specifically PHMs dealing with nutrition of children in preschool age were included.

The data were based on group interviews in which PHMs provided narrative accounts of exemplars from their practice. Participants included must have had experience of nutrition counseling for at least two years. Participants were excluded from the study if they did not give informed consent. Participants were also excluded if they were busy engaged with other tasks.

Due largely to the time and resource constraints it was expected that approximately 18 participants would be interviewed. Although the sample size is not a crucial issue for a phenomenological study the researcher believes that this sample provides a reasonable breadth of experiences for the participant group. Twelve participants from Batticaloa district and six participants from Kalmunai district were selected irrespective of their ages.

\section{Ethical considerations}

The researcher obtained ethics clearance from the Ethics Review Committee of the Faculty of Health-Care Sciences of the Eastern University, Sri Lanka and permission from the RDHSs of Batticaloa and Kalmunai. The participants were also informed that they had the right to withdraw at any stage of the study without penalty.

All data collected, including DVDs and written transcripts were kept safe and secure, and would not to be accessed by any unauthorized person. Each interview was conducted using unstructured questions. There was no possibility of physical risk to participants of this study. Measures were taken to safeguard confidentiality, anonymity and the psychological wellbeing of the participants.

\section{Analysis and interpretation}

Interpretive phenomenology is the most appropriate method for this study as a study of human experience. The philosophical underpinnings of interpretive phenomenology have guided the study of exploring the feelings and experience of participants who provide nutrition counseling. In this study, participants' stories were recorded and analyzed using the hermeneutic circle, of dialogue with the text and writing of the interpretation.

The hermeneutic circle represents the art of understanding [8]. Gadamer (1975) lists the notions of hermeneutic circle as understanding, prejudice, linguisticity of understanding, historicity, and the fusion of horizons and lived experience, which are significant in data analysis [8]. In this study, the individual DVDs were transcribed carefully by listening and re-listening. The transcripts were re-read several times to become familiar with the text. We allowed participants to read their transcripts and provide their opinions on the transcripts.

Through frequent reading of individual transcripts, we highlighted many impressive words and phrases. We deeply immersed ourselves in the stories of each individual so that we could really hear their voices and pick up points of real experience. We then formed themes from collectively viewing all words and phrases emerging from the individual stories. In literature 'themes' refer to elements, which occur frequently in the text [6].

\section{Results}

The participants described their experience and feelings in their own words. The researcher refined the themes with the knowledge from his experience and the available literature.

We used the hermeneutic process of re-reading and the hermeneutic circle for identifying the themes of the study. The following major themes have emerged through the interpretation process.

The themes were: (i) habit of fast food, (ii) busy life of mothers and care givers and (iii) lack of knowledge among mothers and care givers and (iv) lack of health care personnel. A sub theme critical financial 
situation was also emerged under the theme busy life of mothers and care givers and another sub theme interference of mother-in-laws in child nutrition was emerged within the major theme, lack of knowledge among mothers and care givers.

\section{Theme: Habit of fast food}

12 participants described about the involvement of fast food in the life style of people in their areas. It can be understood from the participant's own words (Table 1). Although many of the mothers/ care givers do not possess enough knowledge about the harmful effects of fast food, they give preference to their convenience. For example, a participant expressed her experience through her words (Table 1).

\section{Theme: busy life of mothers and care givers}

It was extremely difficult to maintain a healthy life style to people living in the region. Mothers and care givers are busy with their daily household and other tasks. Thus, there was a high possibility of having a busy life among the mothers/ care givers of the children aged 6-36 months. The participants expressed this in their words. An example is given in (Table 1). It was the reply of a participant who was engaged in nutrition counseling to mothers and care givers for last 7 years. A sub theme critical financial situation was also identified during the process of data analysis.

Subtheme- Critical financial situation: Sri Lanka is a developing country where per capita income is relatively low. Many communities in the Eastern province are at a very poor economic level. Many mothers and care givers come from these poor communities where the income is not sufficient for day to day living. Wealthier mothers and care givers were able to seek medical advice for advanced nutrition care.

PHM 5FGD2 described the economic status and the current difficulties of the families in her service area. The families had no clear idea about their future plans. This is due to their concern about ongoing life with financial distress. The following statement represented a PHM's view (Table 1).

\section{Theme: lack of knowledge among mothers and care givers}

The participants told several stories about knowledge level of mothers care givers. Many mothers get advices on child nutrition from laymen, family members and neighbors. Especially, the mothers and care givers of Kattankudy town in Batticaloa, depend on the experienced family members for nutritional management of the family. The nature of the knowledge level of mothers/ care givers can be understood from the actual words of a participant (Table 1). This response indicates the real picture of the knowledge level of the mothers and care givers. A sub themes interference of mother-in-laws was also identified when we performed the analysis.

Sub Theme- Interference of mother-in-laws: In both communities Tamil and Muslim, the experiences women in the household supervise the food preparation and serving to the family. The participants faced many problems in achieving adequate nutritional habits among the mothers and care givers due to the interference of mother-in-laws. It is more common in the Muslim society. For example, the following response is given as a sample of the lived experience of PHMs (Table 1).

\section{Theme: lack of health care personnel}

PHMs are overburdened with their daily routine task and have little time to spend with mothers and care givers to discuss about the nutrition of their children. At present a PHM is assigned to a defined geographical area, but some PHMs cover up the duties of more than one PHM area which are vacant. They are frustrated with workload. The view of a PHM is given as a sample (Table 1).

\section{Discussion}

\section{Habit of fast food}

Undernutrition remains the main nutritional problem among primary school children of the schools in the Colombo district, while overweight and obesity are emerging at an alarming rate, with boys particularly at risk [9]. The participants expressed their grievances on

\begin{tabular}{|c|c|c|}
\hline \multicolumn{2}{|c|}{ Themes and Sub themes } & \multirow{2}{*}{$\begin{array}{l}\text { Participant's Statements } \\
\text { "Mothers are used to the habit of buying foods..... mm...yes.. especially for breakfast. And they said, the } \\
\text { practice is more convenient for them".(PHM } 2 \text { FDG 2: 58-61) }\end{array}$} \\
\hline Theme 1 & $\begin{array}{l}\text { Habit of fast food } \\
\text { (12 PHMs) }\end{array}$ & \\
\hline \multirow{2}{*}{$\begin{array}{l}\text { Theme } 2 \\
\text { Sub theme } 2.1\end{array}$} & \multirow{2}{*}{$\begin{array}{l}\text { Busy life of mothers/care givers } \\
\text { (15 PHMs) } \\
\text { Critical financial situation } \\
\text { (16 PHMs) }\end{array}$} & $\begin{array}{l}\text { "Then they have to make the children to go to school, husband to go for work and herself, to go out ....they } \\
\text { are always busy.....in the mornings, noons....even during the evening times, they are engaged with many } \\
\text { other tasks, they said." } \\
\text { (PHM } 1 \text { FGD 2: 70-74) }\end{array}$ \\
\hline & & $\begin{array}{l}\text { "They ran the family with the daily income of fishing in the Batticaloa lagoon. Now days,.......... it is } \\
\text { impossible to get a few money. .....................The children, two daughters go to school and one son } \\
\text { stays at home. mm........ They too face difficulties in continuing their education." } \\
. \text { (PHM5FGD2: } 54-69)\end{array}$ \\
\hline \multirow{2}{*}{$\begin{array}{l}\text { Theme } 3 \\
\text { Sub theme } 3.1\end{array}$} & \multirow{2}{*}{$\begin{array}{l}\text { Lack of knowledge among mothers/ } \\
\text { care givers } \\
\text { (13 PHMs) } \\
\text { Interference of mother-in-laws } \\
\text { (9PHMs) }\end{array}$} & $\begin{array}{l}\text { "The mothers listen from whoever teaches. But....... } \\
\text { They hear the information via this ear and leave out it through other ear..... } \\
\text { They strongly follow whatever the husband or husband's mother tells." } \\
\text { (PHM } 3 \text { FGD3: 76-83) }\end{array}$ \\
\hline & & $\begin{array}{l}\text { "We tried several times.. but cannot make a change ................... } \\
\text { As they are compelled to obey their husbands, .... they follow the instructions given by husbands' mothers, } \\
\text { and.. they ignore our advices." } \\
\text { (PHM1 FGD 3: 60-67) }\end{array}$ \\
\hline Theme 4 & $\begin{array}{l}\text { Lack of health care personnel } \\
\text { (15 PHMs) }\end{array}$ & $\begin{array}{l}\text { "As you know, we are always occupied and...........busy........ and we cannot visit individual houses to meet } \\
\text { them........ } \\
\text { We need additional staff at least to visit homes twice a week and give individual care and nutrition } \\
\text { counseling." } \\
\text { (PHM 6FGD2: 66-70) }\end{array}$ \\
\hline
\end{tabular}

Table 1: Themes and sub themes. 
fast food habit of mothers and care givers. The mothers and care givers need assistance from others to get rid of this habit, and perform their daily living activities with joy. The personalities of many people do not permit them to change their habits easily [10]. Ten participants said that the mothers and care givers felt guilty for being depended on fast food, but they could not change their habits due to their personality, attitude and life style. This is both a functional and a psychological problem of which needs a level of understanding from participants, families and importantly staff.

Every PHM can encourage her clients to express their views against the habit of fast food. The PHMs can also encourage family members to spend more time with the care of their young children in the family. They can also talk with the mothers and care givers in order to explore the roots of this habit. Further, they can suggest healthy alternative solutions and assist mothers to pick the most suitable solution.

\section{Busy life of mothers and care givers}

All participants stated that issues related to busy life style were the major concerns for mothers and care givers. Nutrition status of the family members is affected much due to alterations in lifestyle [11]. The mothers attempt to satisfy the immediate requirements of food using whatever available easier ways. They do not pay much consideration on nutritive values and the potential harmful consequences. Poverty is one of the main reasons forcing them to lead a busy life.

If they have sufficient money, they will be at home having enough time for caring the children. The critical financial situation is common to the people living in the developing countries [12]. But the daily income of war torn Eastern people is often not sufficient for daily living needs. Once the breadwinner falls sick, the financial situation of the family becomes far more critical. The families suffer difficulties in getting money for their day to day living. This issue emerged as a very significant one in this study.

According to Sinclair and Fawcett (p316), '..... there is a loss of prestige, for example, if a breadwinner has to stop work, or when the head of the family must leave to the spouse, decisions over important matters of child care and finance'[10]. In this study, all participants expressed that the breadwinners of the families were males and there were few families were headed by women. They suffered severe financial distress and struggled with stress.

Health care professionals can play a major role in assisting the families with financial hardship [12]. The health staff especially nurses and midwives can counsel the family about available assistance in critical financial situations. Special arrangements should be made by the government and Non Governmental Organizations (NGO) in order to support these families financially. Health personnel have the great responsibility to counsel these families by suggesting available alternatives to get stability in their financial situation. They can guide families to seek aid from government and NGOs when such schemes are available.

\section{Lack of knowledge among mothers and care givers}

Central to the experience of virtually all participants was the lack of knowledge among mothers and care givers. All PHMs maintained good relationships with mothers and care givers in their areas but fourteen of them were not happy about the knowledge level of the mothers and care givers. The PHMs worried that mothers and care givers had poor knowledge on feeding practices of young children. There were many reasons for poor knowledge, either from health personnel or mothers and care givers side. Staff shortages and heavy workload were some reasons, according to the PHMs. It is something staff should be aware of.

The community based health care services on nutrition counseling to preschoolers is existing at present in Sri Lanka. The available facilities are limited to a certain level only. The Infant and Young Children Nutrition (IYCN) programme covers the nutritional counseling of children up to 2 years of age. All MOH divisions in Sri Lanka follow the programme in order to improve the nutritional status of the children up to 2 years of age. There may be many barriers for adaptation of effective nutritional habits in rearing the children from 6 months to 36 months of age, in Sri Lanka even though the IYCN project is being implemented covering the children of age up to 2 years.

It is mandatory to strengthen the nutrition counseling intervention package for preschool children and investigate the effective strategies in a systematic manner. Effective nutrition counseling promotes consuming nutritive foods which are locally available for lower cost. The farmers, fishermen and other local manufacturers will get benefit and the national income of the country will be increased.

The sub theme interference of mother-in-law in child nutrition needs major attention because it has been affecting child nutrition for long time. Mother-in-law plays vital role in the care of the family. In Muslim community, in order to respect the husband's mother, many families follow the advices of mothers-in-law for all family matters. As an experienced woman, her experience may guide to make the family healthier for more instances. But some mothers-in-law are resistant to accept newer updates on child nutrition. According the participants, the mothers-in- law reject the advices of PHMs and stick on their traditional values and beliefs such as hot food concept.

Sinclair and Fawcett explained clearly that the interference in nursing interventions cause stress, a precursor of anxiety and depression [10]. The PHMs have been affected psychologically because of the mothers-in-laws block the way to reach clients with problems.

\section{Lack of health care personnel}

Sometimes, a PHM covers more than a single PHM area in the Eastern province. It becomes more difficult for PHMs to work in the remote villages need to travel long distances daily. They are overburdened with their routine work, and do not have adequate time for proper individual nutrition counseling. Their grievances in this regard are quite reasonable. So, the policy makers should consider providing more personnel and facilities for community health services.

\section{Conclusion}

Knowing about the clients, as these PHMs describe it, is always situated by time constraints, practical situations, and the nature of the PHM-client-family relationship. The four themes, which emerged in the study, represent four issues in the duty of participants with nutrition counseling in the Eastern province in Sri Lanka. There are many aspects where further studies should be conducted in relation to the area of financial crisis. The impact on the family is one area that could be further explored. In addition, to improve the knowledge of the mothers/ care givers, available assistance from the government departments and NGOs should be explored so that gaps in this knowledge can be better managed.

The PHMs may come to the work with their personal stressors; they may be irritable and lose their self-control. They may express this stress as lack of interest. Therefore further studies would be welcome 
to explore why some PHMs face difficulties in maintaining good relationship with mothers and care givers.

The study was limited to participants from 2 districts in the province, with only 18 participants being interviewed in 3 FGDs. This was mainly due to the constraints of undertaking the study within the time frame allowed. Although the number of participants was not critical to the study findings, it could be well that other themes may have emerged with a larger group.

The study touched on the physical and psychological aspects of these participants up to a certain extent only. Therefore we would welcome further studies to explore the feelings and experience of these participants in regard to the four major issues. In particular there should be further studies to explore the barriers of nutrition counseling such as traditional beliefs about foods and negative attitudes towards the PHMs, in the community.

\section{Acknowledgment}

Financial assistance given by Higher Education for the Twenty first Century (HETC Grant No: HETC/CMB/QIGW3/MED/TOR-04) of Sri Lanka is acknowledged. The technical guidance was provided through a series of research methodology and scientific writing workshops under the HETC project, coordinated by the Faculty of Medicine, University of Colombo.

\section{References}

1. Department of Census and Statistics and Ministry of Healthcare and Nutrition of Sri Lanka. Sri Lanka Demographic and Health Survey-2006-07.
2. Balls $P$ (2009) Phenomenology in nursing research: methodology, interviewing and transcribing. Nursing Times; 105: 31.

3. King PA, Thomas SP (2013) Phenomenological study of ICU nurses' experiences caring for dying participants. West Journal of Nursing Research 35:1292-1308.

4. Thuita FM, Ndegwa K (2011) Engaging Grandmothers and Men in Infant and Young Child Feedingand Maternal Nutrition, Report of a formative assessment n Eastern and Western Kenya, Retrieved January 29, 2012.

5. FitzGerald M (2001) Study Guide-Interpretive and Critical Research in Nursing, the University of Adelaide, Adelaide.

6. van Manen M (1990) Researching lived experience: Human science for an action sensitive pedagogy. State University of New York Press: USA.

7. Streubert HJ, Carpenter DR (1999) Qualitative research in nursing: Advancing the humanistic perspectives, (2ndedtn), Lippincott, Philadelphia.

8. Annells M (1996) Hermeneutic phenomenology: Philosophical perspectives and current use in nursing research. Journal of Advanced Nursing 23: 705-713.

9. Jayatissa R, Mutowo R, Diana A (2006) Assessment of nutritional status among children under five years in World Vision Lanka operational areas in Ampara district.

10. Sinclair HC, Fawcett JN (1991) Altschul's Psychology for Nurses, (7thedtn), Bailliere Tindall, London.

11. Swaminathan M (1999) Handbook of food and Nutrition, Bangalore Printing and Publishing Co. Ltd., Bangalore.

12. Walsh M (1997) Watson's clinical nursing and related sciences, (5thedtn), Churchill Livingstone: London. 